\title{
ALTERNATIVE MASTER NARRATIVE: THE AVENUE LEADING TO GENERATIVITY
}

\author{
Lili Khechuashvili, Mariam Gogichaishvili \\ Tbilisi State University, Georgia \\ E-mail: lili.khechuashvili@tsu.ge, mariam.gogichaishvili307@sps.tsu.edu.ge
}

Tamari Jananashvili

Training Center of Justice of Georgia, Georgia

E-mail: tjananashvili@tcj.gov.ge

\begin{abstract}
Two independent mixed method studies are aimed at exploration of the major process of negotiation with an internalization of the master narrative, which assists as the cultural framework for narrative identity development. It analysed and compared the data obtained from same-sex desire individuals, ex-convicts and ordinary Georgian citizens, and traced the process of autobiographical reasoning and negotiation with autobiographical master narrative as the mean for development alternative master narrative, which, in turn, serves as the avenue for overcoming stigma, achieving resocialization and generativity, and coming in accord to one's own identity. The comparative analysis addressed the following questions: How do research participants construct biographical alternative master narrative? Does this narrative lead to generativity? Does autobiographical reasoning mediate development of alternative master narrative? Altogether 30 life stories (16 same-sex desired persons and 14 ex-convicts) or 840 narratives were coded for narrative autobiographical reasoning, generativity, as well as for narrative structure (redemption and contamination). Besides, thematic comparative analysis was carried out. Qualitative analysis revealed the main thematic lines of the life stories, such as stigmatization and victimization, family relations, hard childhood experiences, urge for generativity, resocialization and identity formation. Research participants from both samples constructed their life stories or narrative identities through bringing on the surface the implicit master narrative and creating their own alternative one via either shifting and replacing the events or modifying sequences of the events included in the normative life story or autobiographical master narrative.
\end{abstract}

Keywords: alternative master narrative, autobiographical reasoning, generativity, narrative structure.

\section{Introduction}

Human beings are storytellers by nature. They need to tell stories of themselves in order to make sense out of their personal experiences and to come into piece with oneself as well as to external world and broader society. The stories constructed for this purpose have been widely explored by narrative researchers (cf. McLean and Syed, 2015) and are known as life stories or narrative identities. McAdams (2013) introduced the concept of narrative identity as psychosocial construction 
OF PSYCHOLOGY

IN THE $21^{\text {st }}$ CENTURY Vol. 12, No. 2, 2018

76

that emerges through person-culture complex dynamic relationship (Gregg, 2007) and implies that individual who crafts her/his life story is always placed into social-political, cultural and historical context, which interacts and influences the process of narrative engagement (Hammack, 2008). This process leads to the development of narrative identity in accord to master narrative (McLean \& Syed, 2016) in given culture or, as authors stated (cf. Khechuashvili, 2016; McLean \& Syed, 2016; McAdams, 2013), one can deviate from dominated script and develop one's or one's group's own master narrative, which, in turn, will be treated as alternative from broader society. As McLean and Syed (2016) theorized, alternative master narrative can be created on the group level and such narratives differ due to between-group differences.

Research on cultural peculiarities of dominated life scripts or biographical master narratives, as McLean and Syed (2016) referred and their alternative developments, is relatively new in Georgian contexts (see Khechuashvili \& McLean, in prep.; Jananashvili, Khechuashvili, \& Gogichaishvili, 2018; Gogichaishvili, Khechuashvili, \& Mestvirishvili, 2016; Tchumburidze \& Khechuashvili, 2016; Khechuashvili, 2015b).

The extensive empirical knowledge on interaction of identity and generativity, as crucial facet of mature, socially adapted individuals is aggregated (McAdams, 2013). If summarize the research on relationships of narrative identity and generativity, it can be stated that personal narrative coherence and structure, namely coming to a sense of positive resolution of negative events, positively associates with relatively higher scores on generativity and its components (McAdams \& Aubin, 1992; McAdams, Diamond, \& Aubin, 1997; McAdams, 2013). In other words, increasing amount of empirical data proves that content of one's life story or narrative identity which, as mentioned, is a product of negotiation and internalization with broader master narrative (McLean \& Syed, 2016), and the ways one structures one's life story reliably predicts and exerts its influence on the ways of both, self-perception and relational patterns, as well as on one's overall wellness, mental health, and social adjustment (see Adler \& McAdams, 2007; Adler, Skalina, \& McAdams, 2008; Adler, 2012).

As for the research on generativity in Georgian context, only one study is available (Khechuashvili, in press) addressing the associations between posttraumatic growth, rumination and generativity, however, no study has tied together development of alternative master narrative and urge for generativity, as manifestation of socialization or resocialization.

The presented research thus, lined up with previous research on Georgian master narrative and dynamics of development of alternative master narratives and aims at exploration the commonalities and differences in the trajectory of biographical alternative master narrative developed by same-sex desire individuals and ex-convicts based on their unique experience, traces the role of autobiographical reasoning in the process and reaching the generativity meanwhile.

\section{Master and Alternative Narratives}

The general idealized life models implicitly existing in the society in given time, are known as master narratives (Thorne \& McLean, 2003). The concept is seen as consistent with the concept of "dominant discourse" employed by social scientists (Hammack, 2008), life script (Berntsen \& Rubin, 2004), dominated cultural script (McAdams, 2013), and life course (Runyan, 1984). Master narrative, unlike personal life story, doesn't belong to any person and represents culturally shaped generalized story (McLean \& Syed, 2016) that dominates in given culture, and reflects the idealized view of "good", acceptable life course within it. Master narrative provides the themes, contents and images for the members of a culture for construction of their own life stories.

Biographical master narrative represents a series of events that take place in a specific order and reflects prototypical life course within a certain culture. It consists of slots and requirements about what can fill the slots. These are culturally important transitional events that are expected to occur within a circumscribed age span in the life course of individual members of the culture (Berntsen \& Rubin, 2004).

Deviation from the main avenue of master narrative is considered as alternative master narrative, which is formed as the different pathway to proceed in life (McLean and Syed, 2016). Through negotiation and reflexive elaboration group of people develop their own master narrative 
that fits more their experiences and identities, and this is known as alternative, such as narratives of same-sex desire individuals (Gogichaishvili, et. al., 2016; Westrate \& McLean, 2010) and Black Vol. 12, No. 2, 2018

Americans (McLean \& Syed, 2016). Basically, existence of alternative master narratives enhances and illustrates the power of dominated master narrative.

\section{Generativity}

Generative concern, as originally defined by Erikson (1963), usually is associated with middle adulthood, when adults high on generativity strive to "nurture, guide, and care for those things and people that will potentially survive the self and thereby contribute positively to the next generation" (McAdams, Diamond, de St. Aubin, \& Mansfield, 1997, p. 680). Based on Erikson's definition of the construct, existing theoretical accounts of generativity and empirical data, McAdams and de St. Aubin (1992) suggested conceptual model of generativity, which views it as combination and of seven psychosocial features that are tightly interwoven. These are: Cultural demand for age-appropriate behaviour, the inner desire targeting needs to attain symbolic immortality and to be needed by others operate together in adulthood to stimulate a conscious concern for the next generation, which in combination with a belief in the worthwhileness of human life for the future, may lead a person to generative commitment and finally to generative action, as expressed in behaviours aiming at creating or maintaining worthy products and outcomes that may be offered to the next generation as a gift, and exceed one particular life. The last feature of the model is Generative narration that implies the way in which the adult person understands and narrates the story of his or her generative efforts and projects in the context of his or her self-defining life story (McAdams \& de St. Aubin, 1992, McAdams, Hart, \& Maruna, 1997).

\section{Research Objectives}

The main research question was: How do research participants construct alternative biographical master narrative? Also, it aimed at answering the following questions: Does this narrative lead to generativity? And does autobiographical reasoning mediate development of alternative master narrative? Hence, the research objectives were to explore life story narratives of same-sex desire individuals and those with imprisonment experiences, to trace differences and commonalities in the structure as well as thematic lines of their stories, and to observe the alternative master narratives constructed by research participants and the ways they are connected with autobiographical reasoning and generativity.

\section{Methodology of Research}

\section{General Background}

The research was designed in narrative psychology framework, namely, the narrative identity model (McAdams, 2013) is employed, which is defined as the subjective reconstruction of the autobiographical past and imagined future in such ways as to provide one's life with some degree of unity, purpose, and meaning. The study was exploratory endeavour aiming directly to explore the life stories, as they negotiate with larger cultural narratives.

Narrative research strategy was taken for four reasons: First, storytelling is a common, necessary, adaptive behaviour. Human beings are frequent and natural storytellers (Bruner, 1991), and storytelling is inseparable from one's existence. Second, narrative approach provides temporal and sequential order to the telling events, reflecting the real-life circumstances (McLean \& Syed, 2016). Third, narrative provides a uniform metaphor for understanding the individual and the structure. That is, representing both individual and structural factors as storied aligns the two levels of analysis on the same metric, facilitates the ability to connect them and identify the critical processes operating in between. Four, narrative provides the content fillings for the gaps in the gestalt of the quantitatively explored phenomena. 
OF PSYCHOLOGY

IN THE $21^{\text {st }}$ CENTURY Vol. 12, No. 2, 2018 doi: https://doi.org/10.33225/ppc/18.12.75

Sample

Sixty adult participants were sampled based on availability and snowball sampling, all ethnic Georgians. The rest of the participants were recruited from general population based on simple probability sampling (Table 1).

Table 1. Demographics of the research participants.

\begin{tabular}{cccc}
\hline Groups & N & Gender & Mean Age (SD), Range \\
\hline Same-sex desire individuals & 16 & 7 females & $22.8(4.6), 17-34$ \\
Ex-convicts & 14 & 7 females & $40,3(42,4), 34-57$ \\
Controls & 30 & 21 females & $47,6(17), 25-82$ \\
\hline
\end{tabular}

\section{Instrument and Procedures}

Interview Protocol. The Georgian version (Khechuashvili, 2017; Gogichaishvili, et. al., 2016) of McAdam's (2008) Life Story Interview protocol with some modifications was administered. This was a semi-structured interview, which contains questions about key episodes (high, low and turning points, positive and negative childhood, vivid adult memories and mystical/religious experience), challenges (life and health challenges, stories about loss and failure/regret), and future chapter, dreams/hopes and plans.

Demographics. Gender and age of participants were recorded.

Ethical Considerations and Informed Consent. Research participants were recruited through two NGOs targeting needs of particular groups, namely, same-sex individuals were reached through "Identity", whilst ex-convicts were contacted within "Hepa+". Each research participant was informed about goals, topics and format of the study. This followed by presenting the informed consent form. All participants read and signed the written informed consent form. Research assistants answered all the questions regarding research procedures, withdrawal from the study, anonymity and confidentiality, data ownership and publishing.

Place and Time. Interviews were recorded in 2014-2017, mainly in participants' homes or in NGO offices. Each session lasted from 30 min to 2,50 hours.

\section{Narrative Coding}

Coded memories. The story served as the unit of analysis. In each narrative were coded 14 stories: Seven key points, four challenges and the future script. In total 840 memories were coded. Two independent raters coded 196 stories and got acceptable levels of reliability by each coded variable.

Narrative structure. The coding scheme for redemptive and contamination structure of narratives is derived from theoretical writings on redemption scenes and commitment scripts (e.g., Carlson, 1988; McAdams, Diamond, de St. Aubin, \& Mansfield, 1997). The story was rated as having redemptive structure and was assigned code 1 if there was transition from negative scene toward positive one either in causal or time sequential mode $(k=.95)$. The code 0 was assigned to the narrative if there was no such sequential transformation in the storytelling (Khechuashvili, 2016c, 2017; McAdams, 2008). The story where positive event ended up with negative outcome, was rated as contamination sequence and was assigned code $1(k=.82)$, otherwise it was qualified as 0 .

Autobiographical reasoning measured via sophistication of meaning was coded based on McLean and Pratt's (2006) scheme. Each story was coded on a 4-point scale that represents the degree of meaning-making $(k=.93)$. A score of 0 was assigned to narratives that contained no 
explanation of the meaning of the event to the self. Narratives were scored as 1 if there was mentioned a lesson that the narrator learned from the event. A score of 2 was assigned to stories that Vol. 12, No. 2, 2018 contained "vague meaning"; Narrative of this sort describes some growth or change in the self, but the specifics of the change is not clear. Narratives were scored as 3 if there was evidence that the narrator had gained specific emotional, psychological, or relational insight from the lived experience that was applied to broader areas of his/her life (McLean \& Been, 2009).

Self-Event connections were coded according to the coding system proposed by Pasupathi and Mansour (2006). It implies three categories: No connection to the self, a stability story and a change story $(\mathrm{k}=.73)$.

Generativity. For generativity authors composed the Georgian version of coding scheme. Each memory was coded on 3-point scale (create, preserve, offer). A score of 0 was assigned to the stories that contained no generativity at all. Narratives were scored as 1 if there was mentioned a generational intention or action, which contained assignment of life to people or things $(k=.88)$; A score of 2 was assigned to narratives that contained description of intention/action of preservation, protection, wariness or cultivation $(k=.92)$. Stories were scored as 3 if generational intention/action was offered to someone ruthlessly that means offer to the next generation something, that was created, reserved and will keep its own autonomy $(k=.85)$ (McAdams, 2013).

Normativity of events. The simplified coding scheme for normativity of events is derived based on Georgian cultural script (Tchumburidze \& Khechuashvili, 2016). Narratives were scored as 1 if they contained one of the events from Georgian cultural script (such as marriage, birth of a child, death of a relative, etc.) A score of 0 was assigned to narratives that contained no event from Georgian cultural script $(k=.70)$.

\section{Results of Research}

\section{Quantitative Results}

One-third of narratives were structured with redemption sequence (28.5\%), and majority of narratives had neither redemption nor contamination structure. Besides, the narrative structure was associated with memory type: redemption was revealed in low points, turning points, and life challenges $\left(\chi^{2}(10)=29.647, p=.001\right)$, whilst contamination was found in loss, low points and childhood negative memories $\left(\chi^{2}(10)=82.596, p=.000\right)$. Further, neither narrative structure nor memory type differences were associated with group type (ex-convicts, same-sex desire individuals and controls).

Self-event connections $\left(\chi^{2}(4)=24.195, p=.0001\right.$ ) were found in $1 / 2$ of narratives told by control group, whilst the rest of the participants scored lower; However, same-sex desire individuals linked events and the own self more frequently (26.2\%) than ex-convicts (15.8\%), and these were mainly narratives depicting some changes in the self.

As for sophistication of meaning, same-sex desire individuals scored much higher on meaning making than ex-convicts, however, both groups scored two times lower than controls $\left(\chi^{2}(6)=27.806, p=.0001\right)$. Moreover, same-sex desire individuals (36.3\%) reached insight four times more than ex-convicts (8.8\%), while the latter has got more specific lesson (24\% vs. $15 \%)$ from lived experience.

Further, regarding generativity $\left(\chi^{2}(6)=126.717, p<.001\right)$, more than two-thirds of exconvicts $(79 \%)$ strived to preserve what remained in their lives, whilst only $8 \%$ of same-sex desire individuals had same intention. However, the latter has nothing to offer, unlike $1 / 4 \mathrm{of}$ ex-convicts. Both groups urged for creation almost equally ( $24 \%$ vs $34 \%$ ).

Stories told by same-sex desire individuals contained the least number of normative events (20\%), whilst ex-convicts score a bit higher (24\%), and more than half of controls (55\%) told stories containing normative events $\left(\chi^{2}(2)=8.537, p=.014\right)$. 
OF PSYCHOLOGY

IN THE $21^{\text {st }}$ CENTURY Vol. 12, No. 2, 2018

\section{Qualitative Results}

Qualitative analysis revealed the main thematic lines of the life stories in both groups, such as stigmatization and victimization, family relations, hard childhood experiences, urge for generativity, resocialization and identity formation.

Same sex desire individuals' and ex-convicts' narratives shared memories containing domestic violence as well as psychological and/or physical violence from others:

I saw my father holding a glass... He wanted to throw it at my mom. I yelled at him to stop. He looked at me and continued swearing. I yelled again, grabbed the knife and asked him to put glass down, otherwise I was ready to kill him. And suddenly, he slapped me in the face. I dropped the knife. He took it and chased me screaming like a madman: "I will show you who to kill!" (Female, 22).

Both groups became stigmatized and oppressed due to sexual orientation or penitentiary experience and their narratives are saturated with memories of stigmatization of various kinds.

I've got a job. They gave me an office and I was so happy, but my family laughed at me. They don't believe that I can still achieve something. (Female, 35).

When I was going to the university restroom, guys standing nearby told me that there is no place for me there and I must go upstairs where girls' restroom was located (Male, 19).

Generativity was one of the major thematic lines in narratives of both samples. Research participants tried their bests to share their experience to others, to assist them to proceed in life, to mentor them and show the pathway to avoid similar difficulties they went through by themselves. Ex-convicts told the stories to illustrate how to avoid their mistakes and not to end up in prison.

I agreed on the interview not because I want to release my emotions, but to be useful to someone else... I truly want... Maybe this research will change somebody's mind and they will choose not to take this path (Male, 34).

Ex-convicts told stories of moving on dead circle, as described by Maruna (1997). It should be mentioned that since the sample consisted of those who made break through this circle, their stories were saturated with themes of getting out of jail life without coming back.

When you are getting out of jail, first step is to start your life from scratch. You should analyse your mistakes. Since you are out, you may forget what you have been through... I always reflect on my experience, thinking not to step on the same path again, and not to get into the same circumstances. As I already mentioned, you should first analyse your problems and mistakes in order to move forward (Male, 35).

As for same-sex desire individuals, their narratives were marked with themes of struggles of becoming aware and forming their sexual identity:

I was in a TV show and there was discussion about homosexual people. It was horrible. I asked for a microphone to speak up. I was courageous not for myself... I mean, individuals should not be going through that what I've gone through. I spoke on behalf of all... If I were a thirteen-years old guy, sitting there in the audience, hearing something like that, it would have changed my life. But there was no one for me there (Male, 27).

Besides thematic lines, stories were analysed in the context of cultural life scripts and alternative paths research participants took to maintain either their niche in the society or self-image and identity. As close reading of interview transcripts revealed, in both groups told stories were saturated with elements of given group's alternative master narrative alongside with normative events. In case of ex-convicts these were the stories of how they had got caught, imprisonment experience, court, breaking up with the family or romantic partner, and remarrying after term in prison. As for the same-sex desire individuals, their distinguished stories were about abuse in childhood, coming out, leaving the church and being abandoned by friends and/or relatives, and starting new life full of new commitments. 
When I stated that I'm gay, I lost everything. I lost some part of my family and other people as we... I lost something others possess... For instance, my family never neither will accept Vol. 12, No. 2, 2018 my boyfriend nor admit that he exists. When one wants to introduce his/her beloved one to one's family, family members are happy, bringing gifts and having fun... I will not have all these. I lost acceptance and loyalty from others. I lost the power, which is provided by culture. Culture empowers the man, however, when others see that man declines this force, they do not understand him... I lost this power. It still hurts a lot (Male, 27).

\section{Discussion}

Thus, research participants told one-third of stories in redemption manner that replicates other studies conducted on Georgian samples (Khechuashvili, in press; Jananashvili, et. al., 2018; Gogichaishvili, et. al., 2016; Khechuashvili, 2015b). Besides, such manner of telling one's experience was associated with the type of the memory one has told. Namely, people construct their nadir, turning and challenging experiences in redemptive structure.

Although there were no between group differences in structuring one's life experiences, samesex desire individuals and ex-convicts differed in terms of elaboration of told experience: Same-sex desire individuals were able to relate experiences and their selves more than ex-convicts. They reached more insights and found meanings in their past, especially in the experiences depicting some change in their personality or lives. This corresponded to the theoretical framework and empirical data on negotiation with master narrative and development narrative identity (McLean \& Syed, 2016; McLean \& Syed, 2015). Those who reached higher awareness of pressing master narrative from culture, were forced to elaborate and negotiate more with dominated script, to separate themselves from it and to make effort to develop their own, alternative narrative. This, in turn, implied more autobiographical reasoning that lead to incorporation of important life events in one's self. Hence, same-sex desire individuals reached more understanding of these experiences, as having meaning that leads to better understanding of themselves.

If the distribution and proportion of normative events in life stories are observed, it would be found that same-sex desire individuals had the least number of such stories, that suggested they deviated more from dominated script than other groups, however, ex-convicts scored much lower than controls. Considered the trajectory of life scripts of the two groups, they differed substantially from each other: Ex-convicts were forced to deviate from regular pathway at some turning point that was imprisonment and prison experience, however, they tried their best to go back to normal life, as they put it, to fit in society again. In other words, they strived to reserialize through starting the new families, new jobs, and being enrolled in community life. The main tool of so doing for these participants was being generative - to serve people and community, to care for families and children, to preserve what is left (their identities, relationships, assets) after imprisonment and all negative experiences they gained. In contrary, same-sex desire individuals had nothing to offer to the community and broader society, however they strived to create something new. Moreover, they did not try to fit in traditional path of living unlike ex-convicts. Through both, linking life changing experiences and their selves to each other and searching and finding the meaning in those experiences, reached new understandings and new images of themselves that led them to development of alternative master narrative. Thus, ex-convicts life trajectory started as normative as controls did, deviated at some point due to imprisonment and after they were released, has gone back to "normal" or followed master narrative again, whilst same-sex desire individuals started from the realization that they did not belong there and from the very beginning constructed their identities in the process of development of their own, alternative master narrative against culturally determined dominated script.

As for generativity, it served as one of the main tools of fitting back into master narrative for ex-convicts, however, same-sex desire individuals showed less intention to be generative. The explanation of such differences can be distilled to age range of research participants (see Table 1). As Erikson (Erikson, 1959; McAdams \& de Aubin, 1992) suggested, people care for generativity starting from mid 30s. Hence, same-sex desire individuals were too young to be as generative as ex-convicts and it seems totally rational that they had nothing to offer to community so far. 


\section{Conclusions}

The main outcome of the presented study is that ex-convicts as well as same-sex desire individuals coming to the point when they must create group-level alternative master narrative in order to come in accord to one's identity and inner self as well as to broader society. These two groups differed on the levels of elaboration of lived experience, searching for meaning and autobiographical reasoning, however, they shared themes of stigmatization, overcoming the stigma and resocialization through generative action. The latter was observed as caring for others, mentoring younger generation, starting new families and rearing the children. To conclude, in either case, individuals had to deviate from dominated cultural script in order to achieve harmony with oneself and, at least, with reference group and broader society at some point.

\section{Acknowledgements}

Sincere gratitude goes to Shota Rustaveli National Foundation (Georgia). The study was accomplished with its financial support in frame of the Young Scientists' Research Grant ("Self and Society: Personal and Master Narratives, and Social Adaptation," Grant ID: YS-2016-8).

\section{References}

Berntsen, D., \& Rubin, D. C. (2004). Cultural life scripts structure recall from autobiographical memory. Memory \& Cognition, 32, 427-442.

Bruner, J. (1991). Life as Narrative. Social Research, 71 (3), 691-710.

Erikson, E. H. (1963). Childhood and society $\left(2^{\text {nd }}\right.$ Ed.). New York: Norton.

Erikson, E. H. (1959). Identity and the life cycle: Selected paper. Psychological Issues, 1 (1), 5-165.

Gogichaishvili, M., Khechuashvili, L., \& Mestvirishvili, M. (2016). Stigma, sexual identity and life story. GESJ: Education Sciences and Psychology, 4 (41), 93-121. http://gesj.internet-academy.org.ge/download. php?id=2826.pdf (Written in Georgian Language).

Gregg, G. S. (2007). Culture and identity in a muslim society. Oxford University Press, Oxford, New York.

Khechuashvili, L., \& McLean, K. (in prep.). Transgenerational variation of master narratives in Georgia.

Khechuashvili, L. (2018). Event type, autobiographical reasoning and intraindividual variation of the personal narrative across time. GESJ: Education Sciences and Psychology, 2 (48), 9-33.

Khechuashvili, L. (2016c). Redemption structure of life story narratives and posttraumatic growth (The case of 2008 IDPs). GESJ: Education Sciences and Psychology, 3 (40), 69-97 http://gesj.internet-academy. org.ge/download.php?id=2768.pdf (Written in Georgian Language).

Khechuashvili, L. (2015b). Tracing emerging master narrative of modern Georgians: Reconstruction through individual life stories. GESJ: Education Sciences and Psychology, 3 (35), 90-106. (Written in Georgian Language).

Hammack, P. (2008). Narrative and the cultural psychology of identity. Personality and Social Psychology Review, 12 (3), 222-247.

Jananashvili, T., Khechuashvili, L., \& Gogichaishvili, M. (2018). Discontinuous life: Imprisonment experience, autobiographical reasoning and generativity. GESJ: Education Sciences and Psychology, 1 (47), 3-36 http://gesj.internet-academy.org.ge/download.php?id= 3057.pdf\&t=1 (Written in Georgian Language).

McAdams, D. P. (2008). Personal narratives and the life story. In O. P. John, R. W. Robins, \& L. A. Pervin (Eds.), Handbook of Personality: Theory and Research, $3^{\text {rd }}$ ed. (pp. 242-262). New York, London: Guilford press.

McAdams, D. P. (2013). The redemptive self: Stories Americans live by. Revised and expanded edition. Oxford University Press.

McAdams, D. P., \& Aubin, E. St. (1992). A theory of generativity and its assessment through self-report, behavioral acts, and narrative themes in autobiography. Journal of Personality and Social Psychology, 62, 1003-1015. 
McAdams, D. P., Diamond, A., de St. Aubin, E., \& Mansfield, E. (1997). Stories of commitment: The psychosocial construction of generative lives. Journal of Personality and Social Psychology, 72(3), 678-694.

McAdams, D. P., Hart, H. M., \& Maruna, S. (1998). The anatomy of generativity. In D. P. McAdams and E. de St. Aubin (Eds.), Generativity and adult development: How and why we care for the next generation (pp. 7-43). Washington, D.C.: APA Press.

McLean, K. C., \& Been, A. V. (2009). Processes and content of narrative identity development in adolescence: Gender and well-being. Developmental Psychology, 45 (3), 702-710.

McLean, K. C., \& Pratt, M. W. (2006). Life's little (and big) lessons: Identity statuses and meaning-making in turning point narratives of emerging adults. Developmental Psychology, 42 (4), 714-722.

McLean, K. C., \& Syed, M. (Eds.) (2015). The Oxford handbook of identity development. Oxford University Press.

McLean, K. C., \& Syed, M. (2016). Personal, master, and alternative narratives: An integrative framework for understanding identity development in context. Human Development, 58, 318-349.

Pasupathi, M., \& Mansour, E. (2006). Adult age differences in autobiographical reasoning in narratives. Developmental Psychology, 42, 798-808.

Runyan, W. M. (1984). Life histories and psychobiography: Explorations in theory and method. Oxford University Press.

Thorne, A., \& McLean, K. C. (2003). Telling traumatic events in adolescence: A study of master narrative positioning. In R. Fivush \& C. Haden (Eds.), Connecting culture and memory: The development of an autobiographical self, (pp. 169-185). Mahwah, NJ: Erlbaum.

Tchumburidze, G., \& Khechuashvili, L. (2016). Cultural life script: Georgian version. GESJ: Education Science and Psychology, 4 (41), 19-46.

Weststrate, N. M., \& Mclean, K. C. (2010). The rise and fall of gay: A cultural-historical approach to ay identity development. Memory, 18 (2), 225-240.

Received: November 25, 2018

Accepted: December 23, 2018

\begin{tabular}{|c|c|}
\hline Lili Khechuashvili & $\begin{array}{l}\text { Ph.D in Psychology, Associate Professor, Tbilisi State University, 11, I. } \\
\text { Chavchavadze ave, 0194, Tbilisi, Georgia. } \\
\text { E-mail: lili.khechuashvili@tsu.ge } \\
\text { Website: www.tsu.ge }\end{array}$ \\
\hline Mariam Gogichaishvili & $\begin{array}{l}\text { MA, Postgraduate Student, Tbilisi State University, 11, I. Chavchavadze ave, } \\
\text { 0194, Tbilisi, Georgia. } \\
\text { E-mail: mariam.gogichaishvili307@sps.tsu.edu.ge } \\
\text { Website: www.tsu.ge }\end{array}$ \\
\hline Tamari Jananshvili & $\begin{array}{l}\text { MA, Trainer, Training Center of Justice of Georgia, 3a, Sandro Euli st, Tbilisi, } \\
\text { Georgia. } \\
\text { E-mail: tjananashvili@tcj.gov.ge } \\
\text { Website: http://thirdauthor.com }\end{array}$ \\
\hline
\end{tabular}

